\title{
Acetyl-Cholinesterase inhibitor as Add-On Medication in Schizophrenia: A controlled study
}

\author{
Saeed Shoja Shafti ${ }^{1 *}$ and Abbas Azizi Khoei ${ }^{2}$ \\ ${ }^{1}$ University of Social Welfare and Rehabilitation Sciences (USWR), Iran \\ ${ }^{2}$ Psychiatrist, Razi Psychiatric Hospital, Iran
}

*Corresponding author: Saeed Shoja Shafti, Full Professor of Psychiatry, University of Social Welfare and Rehabilitation Sciences (USWR), Razi Psychiatric Hospital, Tehran-Iran.

Received Date: June 19, 2019

Published Date: July 10, 2019

\begin{abstract}
Objective: Problem with memory and attention is a neglected aspect of schizophrenia. The most affected domains are attention, working memory and semantic memory. The impairments are, like the negative symptoms, basically stable and independent of the positive symptoms. Since such deficits do not respond to antipsychotics, during the past years some approaches have been done by different acetylcholinesterase inhibitors. Assessment of the effectiveness of rivastigmine, as an add-on therapy, on clinical symptoms of schizophrenia, was the main objective of the present study.
\end{abstract}

Methods: 46 male inpatients, with diagnosis of schizophrenia, entered a 12-week, double-blind, clinical trial for random assignment to placebo or rivastigmine, as adjuvant to their current antipsychotic medication. 'Positive and Negative Symptom Scale (PANSS)' and 'Mini Mental State Examination (MMSE)' had been used as the main outcome scales. 'Clinical Global Impressions- Global Improvement (CGI-I)' and 'Extrapyramidal Symptom Rating Scale (ESRS)' had been used as the ancillary scales.

Results: According to the findings, except than significant enhancement of MMSE by rivastigmine $(\mathrm{p}<0.001)$, no significant improvement in positive, negative and general psychopathology of schizophrenia was evident in the target and control groups. Also, except than significant enhancement of CGI-I by rivastigmine in intra-group analysis, no significant improvement was apparent in between- group analysis. ESRS, too, did not display any significant alteration in either group. Finally, effect size (ES) analysis exhibited a large improvement of MMSE by means of rivastigmine.

Conclusion: Disregard to positive or negative symptoms, rivastigmine can significantly improve the cognitive function of schizophrenic patients, which may be favorable for psychosocial intervention or rehabilitation of this group of patients.

Keywords: Schizophrenia; Acetylcholinesterase inhibitors; Rivastigmine

\section{Introduction}

While around $0.3-0.7 \%$ of people suffer from schizophrenia at some point in their lifetime [1], it causes approximately $1 \%$ of worldwide disability [2]. In 2000, the World Health Organization declared that the incidence and prevalence of schizophrenia is approximately comparable around the world, with age-standardized prevalence per 100,000 populations ranging from 343 in Africa to 544 in Japan and Oceania for men [3]. Schizophrenia is a mental disorder, which is usually characterized by strange social behavior and lack of insight. Its diverse clinical features have caused a doubt that whether such a diagnosis characterizes a solitary disorder or a collection of separate syndromes [4].
In addition, the mean life expectancy of persons suffering from this illness is 10 to 25 years lesser than the mean life expectancy of people without that problem [5]. Perhaps, this is due to higher risk of suicide and missed somatic complications among this group of patients [6]. Besides, problems in short-term and long-term memory, disturbed social communication, and unemployment, are the common complications of schizophrenia [7,8]. Recently, lots of efforts have been done to recognize and manage the prodromal phase of schizophrenia, which may be identified about thirty months in advance of overt psychosis [9]. While specific care has been paid to the role of dopamine in the mesolimbic circuit of the brain, the dopamine theory is now supposed to be imperfect [10]. 
Specific attention, also, has been paid to the role of glutamate and its receptor in schizophrenia, mostly due to abnormal levels of glutamate receptors that has been found in the postmortem brains of schizophrenic patients [11], and the finding that glutamateblocking drugs such as ketamine and phencyclidine may simulate the signs and symptoms of schizophrenia [12]. While antipsychotic drugs remain the basis of management for schizophrenia, the search is now planned for medications that may improve the cognitive problems and negative symptoms of schizophrenic patients. As is known, acetylcholinesterase inhibitors (AChEIs) have long been in use for management of cognitive symptoms of dementia [13].

On the other hand, cognitive problems have been designated in schizophrenic patients from the first reports of dementia praecox up to present-day conceptions of cognitive disorders. Nonetheless, a little is known about how to manage them. While in Alzheimer disease, cholinergic deficit has been found and cholinesterase inhibitors have been utilized to interrupt the progress of memory and cognitive dysfunction, the existing evidence suggests that the cholinergic system may be disordered in schizophrenia, too [14]. It means that, in patients with schizophrenia, changes such as decreased nicotinic and muscarinic receptors in the central cholinergic system may contribute to these cognitive deficiencies. Since such shortages do not usually respond to available neuroleptics, different pharmacological treatments have been developed for enhancement of central cholinergic transmission, for instance with AChEIs [15].

Donepezil, rivastigmine, and galantamine, are cholinesterase inhibitors used to treat mild to moderate cognitive impairment in dementia of the Alzheimer's type [16]. In this regard, cortical acetylcholine (ACh) diminution, as well, has been suggested to relate to psychotic symptoms like visual hallucinations and the amount of diminution is said to be associated with the harshness of the symptoms. Some data proposes that AChEIs may show useful in controlling of visual hallucinations [17]. As augmentative agents, while according to some studies, cholinesterase inhibitors have shown useful influences respecting enhancement of cognitive function [18] or improvement of psychotic symptoms of schizophrenic patients [16], contradictory or unsuccessful trials are existent in this regard $[15,19]$.

Rivastigmine is a parasympathomimetic or cholinergic agent and can be prescribed orally or via a transdermal patch; the latter method decreases the frequency of adverse effects, which usually involve nausea and vomiting. The drug is eliminated through the urine and seems to have few drug-drug interactions [20]. Rivastigmine has shown treatment effects on the cognitive, functional, and behavioral problems commonly associated with Parkinson's and Alzheimer's disease dementias [21]. Particularly, it seems to demonstrate noticeable therapeutic effects in patients suffering from a more violent course of disease, such as those with younger age of onset, unfortunate dietary situation, or those experiencing psychotic symptoms [21].

For instance, the existence of hallucinations appears to be a predictor of particularly strong response to rivastigmine in both of Parkinson's and Alzheimer's patients [22]. These effects might reflect the advantageous effect of additional inhibition of butyryl cholinesterase by rivastigmine [22]. The aim of the present appraisal included evaluation of the safety and clinical effects of rivastigmine, as an adjunctive medication in accompany with antipsychotic drug, in patients with schizophrenia.

\section{Methods}

46 male inpatients with diagnosis of schizophrenia, according to the Diagnostic and Statistical Manual of Mental Disorders, $5^{\text {th }}$ edition [23], after complete description of the method and obtaining signed informed consent, entered into one of the designated groups, for random assignment to placebo or rivastigmine, as adjuvant to their current antipsychotic medication, which included one of the conventional antipsychotics like chlorpromazine, haloperidol, trifluoperazine and perphenazine. All samples had been identified as schizophrenia from at least two years ago.

Exclusion criteria in the existing valuation consisted: Any comorbid or another mental disorder in axis I except for schizophrenia, documented neurological or medical ailment, consumption of depot antipsychotics, or concurrent medicines like antidepressants or mood stabilizers. Similarly, no other psycho-social mediation or psychotropic medication, throughout the survey, was allowable. Due to possible advantages of atypical antipsychotics on cognitive, depressive and negative symptoms of schizophrenia, from one hand, and definitively fewer extra-pyramidal adverse effects by them, on the other hand, so their consumption, as well, had been included as exclusion criteria in the present assessment [24].

Because the field of study was limited to chronic male ward of the hospital, therefore all samples had been chosen among the accessible male inpatients. While the evaluation had been done according to a double-blind design, separation of patients into groups was accomplished based on the number of beds, with odd numbers into target group and even numbers into control group. Evaluator (a skilled psychiatrist), staff and patients, were unaware as regards the prescribed medications, which were filled into similar capsules. Rivastigmine was started at a dosage of $3 \mathrm{mg} /$ day in the $1^{\text {st }}$ week, with bi-weekly increment of $3 \mathrm{mg} /$ day up to $12 \mathrm{mg}$ in the $6^{\text {th }}$ week, and then this dosage was held unbroken up to the end of the assessment.

'Positive and Negative Symptom Scale (PANSS)' [25] and 'Mini Mental State Examination (MMSE)' [26] had been used as the main outcome scales. 'Clinical Global Impressions- Global Improvement (CGI-I)' [27] and 'Extrapyramidal Symptom Rating Scale (ESRS)' [28] had been used as the ancillary scales. The length of the appraisal was twelve weeks, and the cases were evaluated by PANSS, MMSE, CGI-I and ESRS at baseline (week 0), and weeks 6 and 12. Adverse effects of drugs had been examined by another associate psychiatrist at weekly visits or based on the staffs' report.

\section{Statistical Analysis}

Samples were matched regarding baseline characteristics by t tests. Treatment effectiveness, as well, was evaluated by ' $t$ test' 
and 'repeated-measures analysis of variance (ANOVA)' comparing both groups over twelve weeks. Statistical significance was defined as a 2 -sided $\mathrm{p}$ value $<$ or $=$ to 0.05 . With regard to the significant changes, 'Cohen's Standard (d)' and 'Correlation measures of effect size (r)' had been calculated for comparing baseline to end-point alterations. MedCalc Statistical Software version 15.2 was used as statistical software tool for analysis.

\section{Results}

Groups were principally analogous and demographic and diagnostic variables were comparable (Table1). Also, analysis for effectiveness was based on data from identical quantity of samples in both groups. 5 patients in the target group, due to reluctance $(n=2)$ or gastrointestinal problems $(n=3)$, and 5 patients in the control group, due to digestive complications $(n=2)$ or reluctance $(n=3)$ left the study. In keeping with the findings and intra-group analysis, and in comparison, with the starting point, no significant improvement in mean total scores of PANSS was evident as regards the positive, negative and general psychopathology in either group $(\mathrm{p}<0.18, \mathrm{p}<0.44, \mathrm{p}<0.53$ and $\mathrm{p}<0.24, \mathrm{p}<0.49, \mathrm{p}<0.71$, in the target and control groups, respectively) (Table 2) (Figure 1,2).

Table 1: Demographic and Clinical Characteristics of Participants.

\begin{tabular}{|c|c|c|c|c|c|}
\hline $\mathbf{C I}$ & $\mathbf{p}$ & $\mathbf{t}$ & Placebo $\mathbf{n = 1 8}$ & Rivastigmine $\mathbf{n = 1 8}$ & Variables \\
\hline$-3.69,4.59$ & 0.82 & 0.22 & $6.444 .11 \pm$ & $44.56 \pm 5.8$ & Age \\
\hline$-4.27,3.61$ & 0.86 & -0.17 & $23.89 \pm 5.46$ & $23.56 \pm 6.15$ & Duration of illness \\
\hline$-2.05,3.65$ & 0.57 & 0.57 & $15.4 \pm 4$ & $16.2 \pm 4.4$ & PANSS-Positive Symptoms \\
\hline$-7.70,4.70$ & 0.62 & -0.49 & $21.1 \pm 9.1$ & $19.6 \pm 9.2$ & PANSS-Negative Symptoms \\
\hline$-7.76,2.96$ & 0.36 & -0.91 & $38.5 \pm 8.2$ & $36.1 \pm 7.6$ & PANSS-General Psychopathology \\
\hline$-0.97,3.17$ & 0.28 & 1.08 & $23 \pm 3.2$ & $24.1 \pm 2.9$ & MMSE-baseline \\
\hline$-0.17,0.11$ & 0.66 & -0.43 & $3.06 \pm 0.26$ & $3.03 \pm 0.14$ & CGI-I-baseline \\
\hline$-2.06,1.46$ & 0.73 & -0.34 & $9 \pm 2.6$ & $8.7 \pm 2.6$ & ESRS \\
\hline
\end{tabular}

Note: PANSS=Positive and Negative Symptom Scale; MMSE= Mini Mental State Examination; CGI-I= Clinical Global Impressions- Global Improvement; ESRS= Extrapyramidal Symptom Rating Scale.

Table 2: Intra-group Analysis of Different Outcome Measures between Baseline and Week 12.

\begin{tabular}{|c|c|c|c|c|c|c|c|c|c|c|}
\hline Variables & $\begin{array}{c}\text { Rivastigmine } \\
\text { Baseline }\end{array}$ & $\begin{array}{c}\text { Rivastigmine } \\
\text { week 12 }\end{array}$ & $\mathbf{T}$ & $\mathbf{P}$ & $\mathbf{C I}$ & $\begin{array}{c}\text { Placebo } \\
\text { Baseline }\end{array}$ & $\begin{array}{c}\text { Placebo } \\
\text { week 12 }\end{array}$ & T & P & CI \\
\hline $\begin{array}{c}\text { PANSS-Positive } \\
\text { Symptoms }\end{array}$ & $16.2 \pm 4.4$ & $14.2 \pm 4.4$ & 1.36 & 0.18 & $-0.98,4.98$ & $15.4 \pm 4$ & $13.8 \pm 4.1$ & 1.18 & 0.24 & $-1.14,4.34$ \\
\hline $\begin{array}{c}\text { PANSS-Negative } \\
\text { Symptoms }\end{array}$ & $19.6 \pm 9.2$ & $17.2 \pm 9.6$ & 0.76 & 0.44 & $-3.97,8.77$ & $21.1 \pm 9.1$ & $19 \pm 9$ & 0.69 & 0.49 & $-4.03,8.23$ \\
\hline $\begin{array}{c}\text { PANSS-General } \\
\text { Psychopathology }\end{array}$ & $36.1 \pm 7.6$ & $34.6 \pm 6.9$ & 0.62 & 0.53 & $-3.42,6.42$ & $38.5 \pm 8.2$ & $37.5 \pm 7.8$ & 0.37 & 0.71 & $-4.42,6.42$ \\
\hline MMSE & $24.1 \pm 2.9$ & $27.1 \pm 2.1$ & -3.55 & 0.001 & $-4.72,-1.28$ & $23 \pm 3.2$ & $23.1 \pm 3.2$ & -0.09 & 0.92 & $-2.27,2.07$ \\
\hline CGI-I & $3.03 \pm 0.14$ & $2.66 \pm 0.78$ & 1.98 & 0.05 & $-0.01,0.75$ & $3.06 \pm 0.26$ & $3.01 \pm 0.38$ & 0.46 & 0.64 & $-0.17,0.27$ \\
\hline ESRS & $8.7 \pm 2.6$ & $10 \pm 3.4$ & -1.28 & 0.2 & $-3.35,0.75$ & $9 \pm 2.6$ & $10 \pm 2.5$ & -1.17 & 0.24 & $-2.73,0.73$ \\
\hline
\end{tabular}

Note: PANSS= Positive and Negative Symptom Scale; MMSE= Mini Mental State Examination; CGI-I= Clinical Global Impressions- Global Improvement; ESRS= Extrapyramidal Symptom Rating Scale.

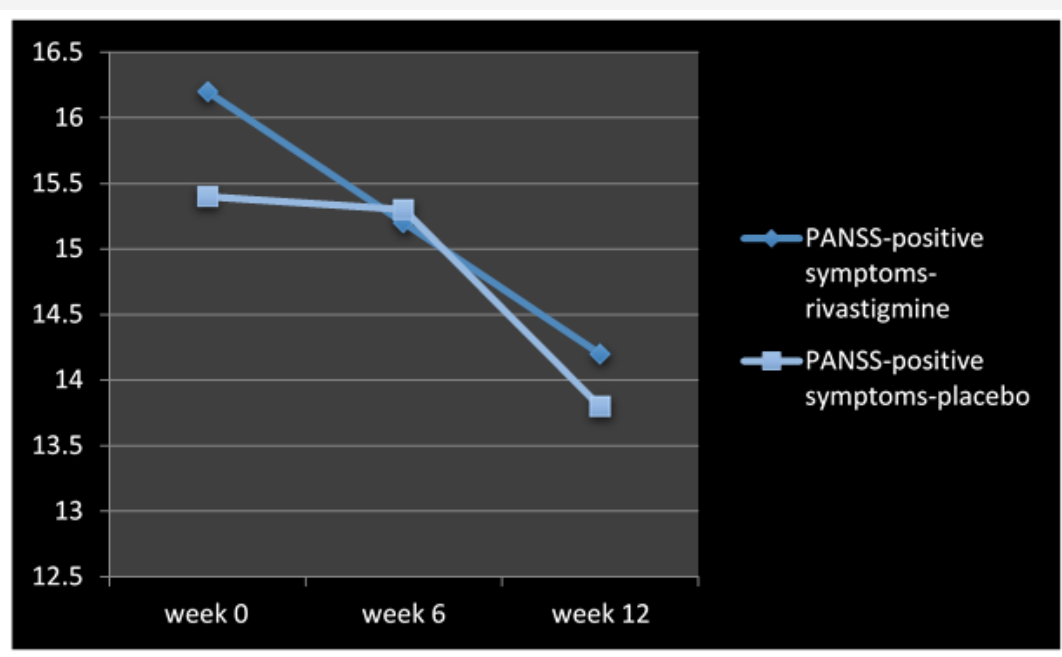

Figure 1: Changes of positive symptoms between baseline and week 12. 


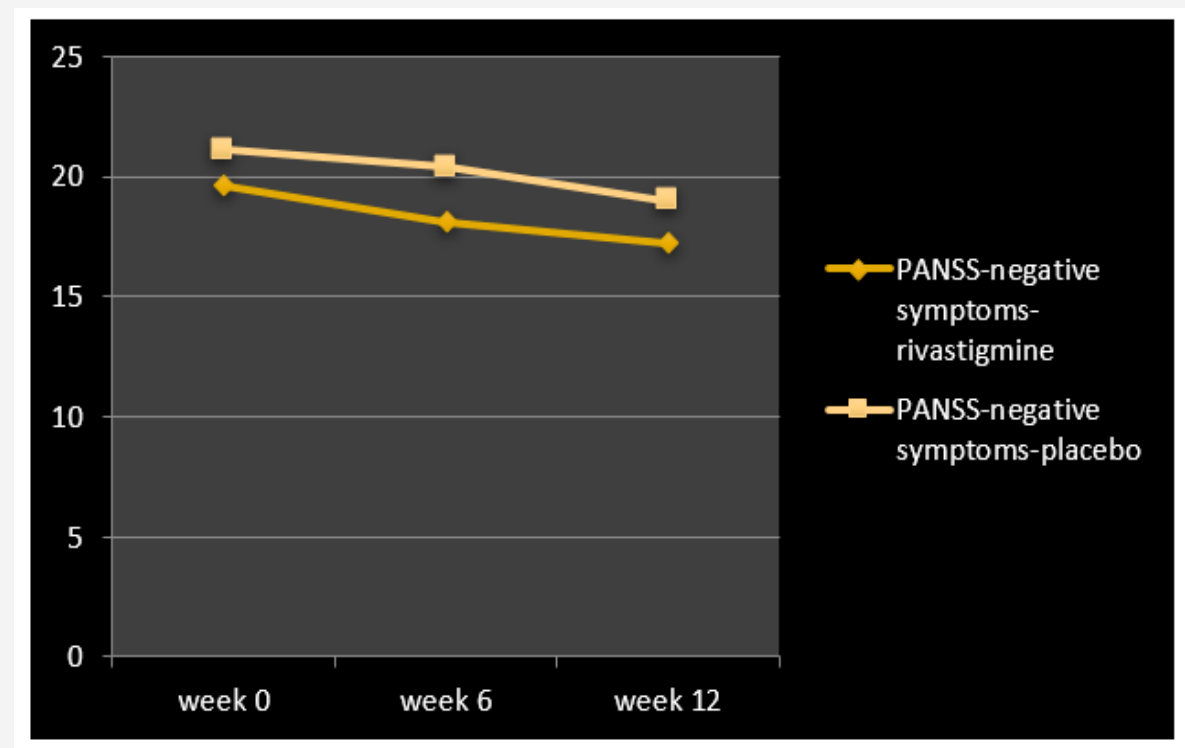

Figure 2: Changes of negative symptoms between baseline and week 12 .

Repeated measure analysis of variance (ANOVA)', as well, could not display any significant alteration regarding the abovementioned evaluations in both groups $[\mathrm{F}(2,51)=0.815 \mathrm{p}<0.44 \mathrm{SS}=6.04$ $\mathrm{MSe}=3.70, \mathrm{~F}(2,51)=0.663 \mathrm{p}<0.51 \mathrm{SS}=13.48 \mathrm{MSe}=10.17, \mathrm{~F}(2,51)$ $=1.34 \mathrm{p}<0.27 \mathrm{SS}=104.15 \mathrm{MSe}=39.01 \& \mathrm{~F}(2,51)=0.668 \mathrm{p}<0.51$ $\mathrm{SS}=4.59 \mathrm{MSe}=3.44, \mathrm{~F}(2,51)=0.833 \mathrm{p}<0.44 \mathrm{SS}=19.70 \mathrm{MSe}=11.83$, $\mathrm{F}(2,51)=1.30 \mathrm{p}<0.28 \quad \mathrm{SS}=125.04 \quad \mathrm{MSe}=48.12$, respectively. Moreover, between-group analysis could not prove any important difference between target group and control group concerning the aforesaid comparisons (Table 3). But with respect to MMSE, though a significant enhancement was evident in the target group at the end of the assessment $(\mathrm{p}<0.001)$, no important improvement was observable in the control group $(\mathrm{p}<0.92)($ Table 2,3) (Figure 3). 'Repeated measure analysis of variance (ANOVA)', too, indicated a significant upgrading in the target group $[\mathrm{F}(2,51)=4.22 \mathrm{p}<0.02$ $\mathrm{SS}=20.26 \mathrm{MSe}=2.40]$ and insignificant change in the control group $[\mathrm{F}(2,51)=1.67 \mathrm{p}<0.19 \mathrm{SS}=32.15 \mathrm{MSe}=9.62]$. Similarly, betweengroup analysis had shown a significant difference between rivastigmine and placeo regarding improvement of MMSE at week $12(\mathrm{p}<0.0001)$, which was manifest from the sixth week $(\mathrm{p}<0.009)$ (Table 3). Additionally, 'split-plot (mixed) design ANOVA' exposed the significant influence of rivastigmine as opposed to placebo on $\operatorname{MMSE}[\mathrm{F}(4,153)=3.89 \mathrm{p}<0.004 \mathrm{SS}=613.80 \mathrm{MSe}=39.48]$.

Table 3: Between-Group Analysis of Different Outcome Masseurs in Weeks 0, 6 and 12.

\begin{tabular}{|c|c|c|c|c|c|}
\hline Variables & Rivastigmine & Placebo & $\mathrm{T}$ & $\mathbf{P}$ & CI \\
\hline PANSS-Positive Symptoms-week 0 & $16.2 \pm 4.4$ & $15.4 \pm 4$ & 0.57 & 0.57 & $-2.05,3.65$ \\
\hline PANSS-Positive Symptoms-week 6 & $15.2 \pm 4.9$ & $15.3 \pm 3.8$ & -0.06 & 0.94 & $-3.07,2.87$ \\
\hline PANSS-Positive Symptoms-week 12 & $14.2 \pm 4.4$ & $13.8 \pm 4.1$ & 0.28 & 0.77 & $-2.48,3.28$ \\
\hline PANSS-Negative Symptoms-week 0 & $19.6 \pm 9.2$ & $21.1 \pm 9.1$ & -0.49 & 0.62 & $-7.70,4.70$ \\
\hline PANSS-Negative Symptoms-week 6 & $18.1 \pm 9.1$ & $20.4 \pm 9.1$ & -0.75 & 0.45 & $-8.46,3.86$ \\
\hline PANSS-Negative Symptoms-week 12 & $17.2 \pm 9.6$ & $19 \pm 9$ & -0.58 & -0.58 & $-8.10,4.50$ \\
\hline PANSS-General Psychopathology-week 0 & $36.1 \pm 7.6$ & $38.5 \pm 8.2$ & -0.91 & 0.36 & $-7.76,2.96$ \\
\hline PANSS-General Psychopathology-week 6 & $35.3 \pm 7.1$ & $37.7 \pm 7.9$ & -0.95 & -0.95 & $-7.49,2.69$ \\
\hline PANSS-General Psychopathology-week 12 & $34.6 \pm 6.9$ & $37.5 \pm 7.8$ & -1.18 & 0.24 & $-7.89,2.09$ \\
\hline MMSE-week 0 & $24.1 \pm 2.9$ & $23 \pm 3.2$ & 1.08 & 0.28 & $-0.97,3.17$ \\
\hline MMSE-week 6 & $26.1 \pm 2.9$ & $23.3 \pm 3.2$ & 2.75 & 0.009 & $0.73,4.87$ \\
\hline MMSE-week 12 & $27.1 \pm 2.1$ & $23.1 \pm 3.2$ & 4.43 & 0.0001 & $2.17,5.83$ \\
\hline CGI-I-week 0 & $3.03 \pm 0.14$ & $3.06 \pm 0.26$ & -0.43 & 0.66 & $-0.17,0.11$ \\
\hline CGI-I-week 6 & $3.00 \pm 0.29$ & $3.05 \pm 0.13$ & -0.66 & 0.5 & $-0.20,0.10$ \\
\hline CGI-I-week 12 & $2.66 \pm 0.78$ & $3.01 \pm 0.38$ & -1.71 & 0.09 & $-0.77,0.07$ \\
\hline ESRS-week 0 & $8.7 \pm 2.6$ & $9 \pm 2.6$ & -0.34 & 0.73 & $-2.06,1.46$ \\
\hline ESRS-week 6 & $9.1 \pm 3.4$ & $10.1 \pm 2.5$ & -1 & 0.32 & $-3.02,1.02$ \\
\hline ESRS-week12 & $10 \pm 3.4$ & $10 \pm 2.5$ & 0 & 1 & $-2.02,2.02$ \\
\hline
\end{tabular}

Note: PANSS=Positive and Negative Symptom Scale; MMSE=Mini Mental State Examination; CGI-I=Clinical Global Impressions-Global Improvement; ESRS $=$ Extrapyramidal Symptom Rating Scale. 


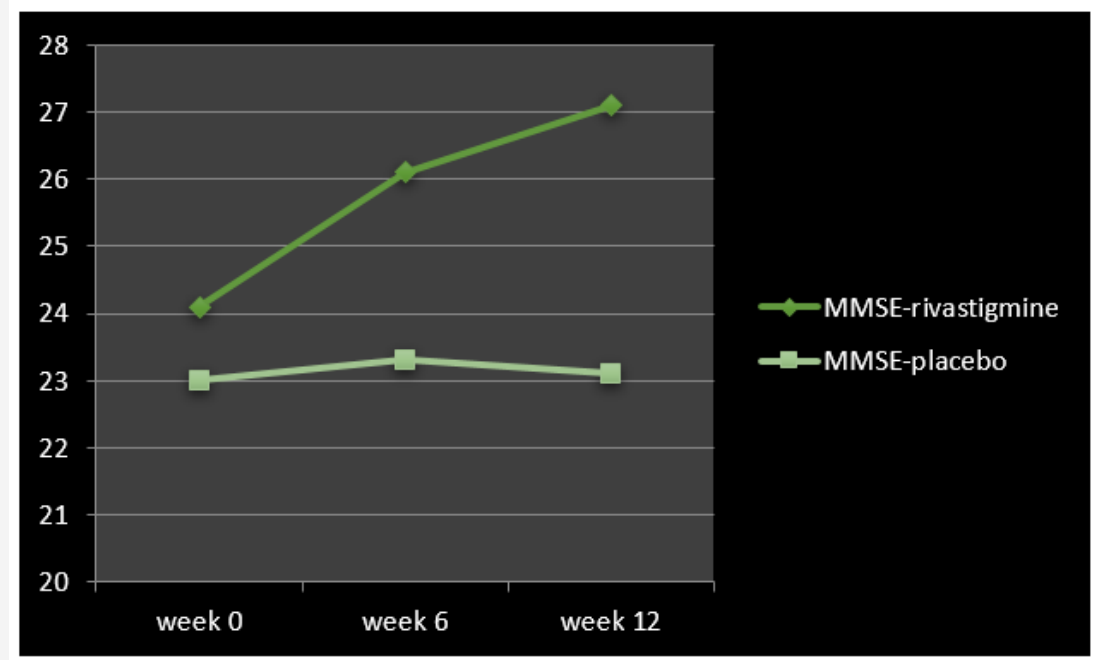

Figure 3: Changes of MMSE between baseline and week 12.

Regarding CGI-I, though according to intra-group analysis a significant progress was obvious in the target group $(\mathrm{p}<0.05)$ (Table 2), it was not similarly significant in between-group analysis (0.09) (Table 3). In this regard, 'split-plot (mixed) design ANOVA', as well, did not show any important difference between rivastigmine and placebo $[\mathrm{F}(4,153)=11.7 \mathrm{p}<0.08 \mathrm{SS}=420.73 \mathrm{MSe}=8.98]$. In connection with ESRS, intra-group and between-group analysis did not illustrate any significant alteration in either group. Since the sample size was small, the effect size (ES) was analyzed for changes in MMSE and CGI- I, at the end of evaluation, which indicated a large $(\mathrm{d}=0.8$ or $\mathrm{r}=0.73)$ and nearly medium $(\mathrm{d}=0.5$ or $\mathrm{r}=0.24)$ improvement by rivastigmine $(1.18 \& 0.50$ and ; $0.66 \& 0.31$, as 'Cohen's d' and 'effect- size correlation r', respectively).

'Post hoc' power analysis presented an intermediate' power $=0.43^{\prime}$ for this assessment, which turned to 'power $=0.77^{\prime}$ as 'compromise power analysis'. The most common side effects of rivastigmine in the current study were vomiting $(n=1)$, nausea $(n=2)$, diarrhea $(n=1)$, and dizziness $(n=1)$. The adverse effects in the control group also were vomiting $(n=1)$, nausea $(n=1)$, and dizziness $(n=1)$. 'Comparison of proportions' did not show any significant difference between two groups regarding the occurrence of adversative effects $(\mathrm{z}=0.80, \mathrm{p}=0.42$, CI $95 \%=-0.38,0.16)$.

\section{Discussion}

Schizophrenia is a main reason of incapacity and is classified as the third-most- disabling illness subsequent to dementia and quadriplegia, and ahead of blindness and paraplegia [29]. Nearly, $75 \%$ of persons with schizophrenia have continuing problems with recurrent psychotic episodes [30]. While antipsychotics are known as the principal treatment for schizophrenia [31-33], they cannot usually improve the cognitive dysfunction and negative symptoms [8-34]. Problem with memory and attention is generally an ignored aspect of schizophrenia. The most affected domains are attention, working memory and semantic memory. These deficits are superimposed on a generalized intellectual deficit averaging about one standard deviation [35]. According to some studies on patients at risk for schizophrenia, such as first-degree relatives and individuals with schizotypal personality disorders, and, also, first-episode patients, information processing deficits are among the earliest clinical or cognitive markers of vulnerability for schizophrenia [36].

Rivastigmine inhibits both butyryl cholinesterase and acetylcholinesterase, unlike donepezil, which selectively inhibits acetylcholinesterase. It is supposed to work by inhibiting these cholinesterase enzymes, which would otherwise break down the brain neurotransmitter acetylcholine [37]. As a semi-synthetic derivative of physostigmine, it has been accessible in capsule and liquid formulations since 1997 [38]. In 2006, rivastigmine came to be the first product approved worldwide for the management of mild to moderate dementia associated with Parkinson's disease [20]; and then in 2007 its transdermal patch became the first patch treatment for dementia [38].

Evaluation of the efficacy and safety of rivastigmine, as an adjuvant to current antipsychotic treatment in schizophrenic patients, was the main objective of the present assessment. Consistent with the findings, though rivastigmine did not display any significant effect regarding amelioration of positive and negative symptoms and general psychopathology of schizophrenia, it could significantly improve the cognitive capacity of patients in the related group, which was marked in the second half of the study. Consequently, about intellectual function, our finding was in accord with the results of $[13,18]$, and in contrast to $[15,19]$.

Such a conclusion may be favorable for enhancement of outcome of psychosocial intervention or rehabilitation of this group of patients, which demands another methodical research for measurement of the pertained functional parameters. As regards the positive symptoms, though the present assessment could not find any valuable effect, Sachin et al. in their review of literature, had found advantageous effects by AChEIs for the management of visual hallucinations in schizophrenia [17], an important finding that demands more systematic studies. Incidentally, it should be mentioned that visual hallucinations are a well-recognized and 
stressful symptom in a range of psychiatric syndromes including schizophrenia.

Visual hallucinations occur, as well, in several neurological illnesses, but are most noticeable in Lewy body dementia, Alzheimer disease and dementia due to Parkinson's disease. While the lifetime prevalence of visual hallucinations in patients with schizophrenia is believed to be more common than what was usually thought, its frequency ranges between 24\%-72\% [39-40]. Though both dopaminergic and cholinergic perturbation have been linked with visual hallucinations, neither of these offers an etiological model. It is suggested that 'acetylcholine in the human brain may modulate the interaction between bottom-up and top-down processing in determining proper neural representations for perceptual inputs' [41].

According to this theory, while low levels of cortical acetylcholine would result in the increased salience of top-down information, high levels would result in over-processing of bottomup stimulus driven information. Considering present concept of the role of cholinergic system in visual pathways and the suggestion that maybe AChEIs are of use in treating visual hallucinations in the abovementioned circumstances, it would appear possible that they may likewise be useful in schizophrenia-related visual hallucinations [17].

On the other hand, Singh et al. [13] had found that the acetylcholinesterase inhibitor plus antipsychotic had displayed profit over antipsychotic and placebo in PANSS negative symptoms, PANSS general psychopathology, along with cognitive function, and the outcomes looked to favor the use of AChEIs , as adjuvant to antipsychotic, on some spheres of cognition and mental state, though due of numerous limitations in the studies the evidence was not strong enough [13]; A finding that was not verifiable in the present appraisal as regards negative symptoms and general psychopathology of schizophrenia. Instead, while in our estimation the CGI-I of the target group had revealed some significant progress in the intra-group analysis, comparing starting point with end point, it was not significant in between-group analysis and repeated measure analysis of variance.

So, a practical conclusion is not presently possible. Friedman, also, had proposed that, based on the existing studies, specific cognitive deficits (like memory and attention) of patients with schizophrenia and schizoaffective disorder are responsive to AChEIs, as add-on therapies. So, he had suggested that whereas a cholinergic approach to ameliorating the cognitive dysfunction of schizophrenia seems worthwhile, there is some preliminary information to support the usefulness of joined acetylcholinesterase inhibitors and allosteric potentiators of the nicotinic receptor [18]. Lenzi et al, also, in an open study found that rivastigmine treatment could result in significant improvements in quality of life, cognitive function, learning, memory, attention, and finally "anergia" in Brief Psychiatric Rating Scale (BPRS) [42].

But in contrast, Sharma et al. [19] in a 24-week randomized, placebo-controlled, double-blind study could not find any significant enhancement in any cognitive measurement by rivastigmine. As stated by him, 'while some cognitive variables exhibited noteworthy alterations in both the placebo and rivastigmine groups, no significant effects were discernible in clinical symptoms or side effects profiles' [19]. Similarly, Voss et al. had concluded that 'thus far randomized, placebo-controlled studies are existent only for rivastigmine and donepezil, and none could reproduce the positive results of earlier appraisals with open designs'; an attitude similar to [43-46], and in conflict with our inference.

While the most common adverse effects of rivastigmine are diarrhea, nausea, vomiting, dizziness, anorexia, weight loss, fatigue, headache, abdominal pain, and somnolence [16], only the first four were evident in our trial. Consistent with literature, since rivastigmine has virtually no potential for interaction, because it is metabolized at the site of action and does not affect hepatic cytochromes [47], it seems to be least possible to cause challenging drug interactions, an issue that can be vital in an elderly population subject to polypharmacy [47].

Nevertheless, worries regarding the potential cardiac adverse effects connected with AChEIs have been upraised subsequent to outcomes from controlled trials of galantamine in mild cognitive impairment (MCI), in which increased mortality was correlated to galantamine [48]. While no definite cause of death was predominant, half the expiries were reported as a result of cardiovascular disorder. So, FDA issued a warning to restrict galantamine in patients with MCI. Anyhow, its relevance to Alzheimer's disease remains indistinct [49]. In this regard, a population-based study using a case-time-control design examined health records for 1.4 million older adults in Ontario and found that treatment with AChEIs was associated with doubling the risk of hospitalization due to bradycardia [49]. Regarding the cognitive measurement in the present assessment, it deserves to be mentioned that while the MMSE is one of the best-known cognitive assessment scales in the mental health field, it has limited utility in those with schizophrenia. The MMSE was developed for those with organic disorders (such as dementia) who tend to have difficulties with orientation and language. Indeed, people with schizophrenia rated with the MMSE frequently obtain scores within the normal range.

So, maybe other fresher measure like 'Brief Assessment of Cognition in Schizophrenia (BACS)', with greater validity and reliability in people with schizophrenia would be a more reasonable choice [49]. Short duration of study, small sample size, and genderbased sampling were among the weak points of the present evaluation. Further methodical studies with large samples, in accompany with inclusive assessment of functioning and disability, are required to determine the clinical usefulness of this treatment approach.

\section{Conclusion}

Disregard to positive or negative symptoms, rivastigmine can significantly improve the cognitive function of schizophrenic patients, which may be favorable for psychosocial intervention or rehabilitation of this group of patients. 


\section{Acknowledgement}

None.

\section{Conflict of Interest}

None.

\section{References}

1. Kapur S (2009) Schizophrenia. Lancet 374(9690): 635-645

2. Brunet Gouet E, Decety J (2009) Social brain dysfunctions in schizophrenia: a review of neuroimaging studies. Psychiatry Res 148(23): 75-92.

3. Ayuso Mateos JL (2013) Global burden of schizophrenia in the year 2000. World Health Organization.

4. Buckley PF, Miller BJ, Lehrer DS, Castle DJ (2009) Psychiatric comorbidities and schizophrenia. Schizophr Bull 35(2): 383-402.

5. Laursen TM, Munk Olsen T, Vestergaard M (2012) Life expectancy and cardiovascular mortality in persons with schizophrenia. Curr Opin Psychiatry 25(2): 83-88.

6. Hor K, Taylor M (2010) Suicide and schizophrenia: a systematic review of rates and risk factors. J Psychopharmacol 2010; 24(4 Suppl): 81-90.

7. Hirsch SR, Weinberger DR (2003) Schizophrenia. Wiley Blackwell pp: 1-481.

8. Shoja Shafti S (2015) Odyssey of Negative Symptoms of Schizophrenia: Rehabilitation vs. Stigmatization. Current Psychopharmacology 4(1): $1-12$.

9. Marshall M, Rathbone J (2011) Early intervention for psychosis. Cochrane Database Syst Rev (6): CD004718.

10. Jones HM, Pilowsky LS (2002) Dopamine and antipsychotic drug action revisited. Br J Psychiatry 181: 271-275.

11. Konradi C, Heckers (2003) Molecular aspects of glutamate dysregulation: implications for schizophrenia and its treatment. Pharmacol Ther 97(2): 153-179.

12. Singh J, Kour K, Jayaram MB (2012) Acetylcholinesterase inhibitors for schizophrenia. Cochrane Database Syst Rev 1:CD007967.

13. Ribeiz SR, Bassitt DP, Arrais JA, Avila R, Steffens DC, et al. (2010) Cholinesterase inhibitors as adjunctive therapy in patients with schizophrenia and schizoaffective disorder: a review and meta-analysis of the literature. CNS Drugs 24(4): 303-317.

14. Voss B, Thienel R, Leucht S, Kircher T (2008) Therapy of cognitive deficits in schizophrenia with acetylcholinesterase inhibitors. A systematic overview. Nervenarzt 79(1): 47-48, 50-52, 54-59.

15. Qaseem A, Snow V, Cross JT Jr, Forciea MA, Hopkins R Jr, et al. (2008) Current pharmacologic treatment of dementia: A clinical practice guideline from the American College of Physicians and the American Academy of Family Physicians. Ann Intern Med 148(5): 370-378.

16. Patel SS, Attard A, Jacobsen P, Shergill S (2010) Acetylcholinesterase Inhibitors (AChEI's) for the treatment of visual hallucinations in schizophrenia: A review of the literature. BMC Psychiatry 10:69.

17. Friedman JI (2004) Cholinergic targets for cognitive enhancement in schizophrenia: focus on cholinesterase inhibitors and muscarinic agonists. Psychopharmacology (Berl) 174(1): 45-53.

18. Sharma T, Reed C, Aasen I, Kumari V (2006) Cognitive effects of adjunctive 24-weeks Rivastigmine treatment to antipsychotics in schizophrenia: a randomized, placebo-controlled, double-blind investigation. Schizophr Res 85(1-3): 73-83.

19. Inglis F (2002) The tolerability and safety of cholinesterase inhibitors in the treatment of dementia. Int J Clin Pract Suppl 127: 45-63.

20. Gauthier S, Vellas B, Farlow M, Burn D (2006) Aggressive course of disease in dementia. Alzheimer>s \& Dementia 2(3): 210-217.
21. Touchon J, Bergman H, Bullock R, Rapatz G N, Nagel J, et al. (2006) Response to rivastigmine or donepezil in Alzheimer's patients with symptoms suggestive of concomitant Lewy body pathology. Curr Med Res Opin 22(1): 49-59.

22. American Psychiatric Association (APA) Diagnostic and Statistical Manual of Mental Disorders. $5^{\text {th }}$ (edn.), American Psychiatric Association, Washington, DC, USA, pp: 663-666.

23. Harrison P, Geddes J, Sharpe M (2010) Lecture Notes: Psychiatry. $10^{\text {th }}$ (edn.) Oxford, Wiley-Blackwell, UK.

24. Kay SR, Opler LA, Lindenmayer JP (1988) Reliability and validity of the Positive and Negative Syndrome Scale for schizophrenia. Psychiatry Res 23(1): 99-110.

25. Folstein MF, Folstien SE, McHugh PR (1975) "Mini- mental state." A practical method for grading the cognitive state of patients for the clinician. J Psychiatr Res 12:189.

26. (1976) Clinical Global Impressions. In: "ECDEU Assessment manual for psychopharmacology, Guy W (Edt.), Rockville, U.S Department of Health, Education, and Welfare, 1976, DHEW Publication NO. (ADM), USA, pp: 76-338.

27. Chouinard G, Ross Chouinard A, Annable L (1980) Extrapyramidal Rating Scale. Can J Neurolog Sci 22: 259-263.

28. Lozano R, Naghavi M, Foreman K, Lim S, Shibuya K, et al. (2012) Globa and regional mortality from 235 causes of death for 20 age groups in 1990 and 2010: a systematic analysis for the Global Burden of Disease Study 2010. Lancet 380 (9859): 2095-2128.

29. Marshall M, Rathbone J (2011) Early intervention for psychosis Cochrane Database Syst Rev 15(6): CD004718.

30. Shoja Shafti S, Gilanipoor M (2016) Olanzapine v Risperidone: A Contrast Between Atypical Antipsychotics Concerning Control of Schizophrenia. Current Psychopharmacology 5(1): 1-8.

31. Shoja Shafti S, Kaviani HA (2016) Comparison Between Quetiapine and Aripiprazole for Treatment of Schizophrenia: A Double-Blind Contrast. Current Psychopharmacology 5(1): 1-8.

32. Shoja Shafti S (2016) Adjunctive Depot Antipsychotic in TreatmentResistant Schizophrenia. Current Psychopharmacology 5(1): 1-8.

33. Shoja Shafti S, Akbari S (2016) Intractability of Deficit Syndrome of Schizophrenia Against Adjunctive Modafinil. J Clin Psychopharmacol 36(1): 45-49.

34. WHO (1992) International Statistical Classification of Diseases and Related Health Problems (ICD-10). Geneva, World Health Organization 1992, pp: 85-109.

35. Lieberman JA1, Perkins D, Belger A, Chakos M, Jarskog F, et al. (2001) The Early Stages of Schizophrenia: Speculations on Pathogenesis, Pathophysiology, and Therapeutic Approaches. Biol Psychiatry 50: 884897

36. Camps P, Munoz-Torrero D (2002) Cholinergic drugs in pharmacotherapy of Alzheimer's disease. Mini Rev Med Chem 2(1): 11-25.

37. Kumar V (2006) Potential medicinal plants for CNS disorders: An overview. Phytother Res 20(12): 1023-1035.

38. Cummings J, Miller B (1987) Visual hallucinations: Clinical occurrence and use in differential diagnosis. West J Med 146(1): 46-51.

39. Bracha HS, Wolkowitz OM, Lohr JB, Karson CN, Bigelow LB (1989) High prevalence of visual hallucinations in research subjects with chronic schizophrenia. Am J Psychiatry 146(4): 526-528.

40. Yu D, Dayan P (2002) Acetylcholine in cortical inference. Neural Netw 15(4-6): 719-730.

41. Lenzi A, Maltinti E, Poggi E, Fabrizio L, Coli E (2003) Effects of rivastigmine on cognitive function and quality of life in patients with schizophrenia. Clin Neuropharmacol 26(6): 317-21.

42. Stip E, Sepehry AA, Chouinard S (2007) Add-on therapy with acetylcholinesterase inhibitors for memory dysfunction in schizophrenia: 
a systematic quantitative review, part 2. Clin Neuropharmacol 30(4) 218-229.

43. Chouinard S, Stip E, Poulin J, Melun JP, Godbout R, et al. (2007) Rivastigmine treatment as an add-on to antipsychotics in patients with schizophrenia and cognitive deficits. Curr Med Res Opin 23(3): 575-583.

44. Ferreri F, Agbokou C, Gauthier S (2006) Cognitive dysfunctions in schizophrenia: potential benefits of cholinesterase inhibitor adjunctive therapy. J Psychiatry Neurosci 31(6): 369-376.

45. Kumari V, Aasen I, ffytche D, Williams SC, Sharma T (2006) Neural correlates of adjunctive rivastigmine treatment to antipsychotics in schizophrenia: a randomized, placebo-controlled, double-blind fMRI study. Neuroimage 29(2): 545-556.

46. Grossberg GT, Stahelin HB, Messina JC, Anand R, Veach J (2000) Lack of adverse pharmacodynamic drug interactions with rivastigmine and twenty-two classes of medications. Int J Geriatr Psychiatry 15(3): 242247.

47. Park-Wyllie LY, Mamdani MM, Li P, Gill SS, Laupacis A, et al. (2009) Cholinesterase inhibitors and hospitalization for bradycardia: a population-based study. PLoS Med 6(9): e1000157.

48. Rosenbloom MH, Finley R, Scheinman MM, Feldman MD, Miller BL, et al. (2010) Donepezil-associated bradyarrhythmia in a patient with dementia with Lewy bodies (DLB). Alzheimer Dis Assoc Disord 24(2): 209-211.

49. Keefe RS, Goldberg TE, Harvey PD, Gold JM, Poe MP, et al. (2003) The Brief Assessment of Cognition in Schizophrenia: reliability, sensitivity, and comparison with a standard neurocognitive battery Schizophrenia Research 68(2-3): 283-297. 